\title{
Exploring household income as a predictor of psychological well- being among long-term colorectal cancer survivors
}

\author{
J. Jason Lundy, Ph.D, \\ University of Arizona College of Pharmacy PO Box 210202 Tucson, AZ 85721-0202 Phone: 740 \\ -550-9508 Fax: 520-626-4063 lundy@pharmacy.arizona.edu
}

Stephen Joel Coons, PhD,

University of Arizona College of Pharmacy PO Box 210202 Tucson, AZ 85721-0202

Christopher Wendel, MS,

Southern Arizona Veterans Affairs Health Care System 3601 S. $6^{\text {th }}$ St. Tucson, AZ 85773

Mark C Hornbrook, PhD,

Kaiser Permanente Northwest 3800 North Interstate Ave Portland, OR 97227

Lisa Herrinton, PhD,

Kaiser Permanente Northern California 2000 Broadway Oakland, CA 94612

Marcia Grant, PhD, and

City of Hope National Medical Center 1500 E. Duarte Rd. Duarte, CA 91010

Robert S Krouse, MD

Southern Arizona Veterans Affairs Health Care System 3601 S. $6^{\text {th }}$ St. Tucson, AZ 85773

\section{Abstract}

Purpose-The purpose of this analysis was to determine the unique contribution of household income to the variance explained in psychological well-being (PWB) among a sample of colorectal cancer (CRC) survivors.

Methods-This study is a secondary analysis of data collected as part of the Health-Related Quality of Life in Long-Term Colorectal Cancer Survivors Study, which included CRC survivors with (cases) and without (controls) ostomies. The dataset included socio-demographic, health status, and healthrelated quality of life (HRQOL) information. HRQOL was assessed with the modified City of Hope Quality of Life (mCOH-QOL)-Ostomy questionnaire and SF-36v2. To assess the relationship between income and PWB, a hierarchical linear regression model was constructed combining data from both cases and controls.

Results-After accounting for the proportion of variance in PWB explained by the other independent variables in the model, the additional variance explained by income was significant ( $\mathrm{R}^{2}$ increased from 0.228 to $0.250 ; \mathrm{p}=0.006$ ).

Conclusions-Although the study design does not allow causal inference, these results demonstrate a significant relationship between income and PWB in CRC survivors. The findings suggest that for non-randomized group comparisons of HRQOL, income should, at the very least, be included as a control variable in the analysis. 


\section{Keywords}

Income; psychological well-being; physical well-being; colorectal cancer

\section{INTRODUCTION}

In 2003, about 20 million families in the US were estimated to have problems paying medical bills; two-thirds of these families had some type of health insurance coverage [1]. Himmelstein et al. [2] found that cancer was the general diagnosis with the highest out-of-pocket medical expenditures leading to bankruptcy in the US in 2001. The results of their analysis suggested that about half of all bankruptcies in the US were due to medical bills. Dranove and Millenson [3] challenged the conclusions of Himmelstein et al. and asserted that medical bills were a cause of closer to $17 \%$ of the bankruptcies analyzed. Nevertheless, both groups of researchers agreed that "too many vulnerable Americans are financially devastated by the cost of illness" [2].

Potential outcomes that fall short of financial devastation deserve attention from researchers and policymakers. Financial strain and disparities in health and well-being associated with income are increasingly being examined among cancer survivors. For example, Ell et al. [4] found that economic stress was associated with lower levels of well-being among predominately Hispanic women with a primary diagnosis of breast or a gynecological cancer. Short and Farley [5] identified income-related disparities in health-related quality of life that were not explained by the effect of health on earnings. This latter study was significant in that it recognized that income is likely to be affected by health, and health is likely to be affected by income (i.e., endogeneity). The relationship between income and well-being for long-term cancer survivors, in whom even successful treatment has potentially negative consequences, can be significant [5].

One group for which this may be the case is long-term colorectal cancer (CRC) survivors. It is estimated that there are over 1.1 million CRC survivors in the US [6]. Many of these individuals, especially those with low-rectal cancers, have received permanent intestinal stomas (ostomies), leaving a critical need to better understand how ostomies affect their lives and well being. Ostomies are the surgical exteriorization of the bowel to the anterior abdominal wall, allowing intestinal waste to flow directly into an external pouch (appliance). A long history of research has addressed the physical and psychosocial consequences of having CRC with or without an ostomy [6-8].

Although substantial evidence links higher levels of socioeconomic status (SES) to higher levels of health status in a variety of populations [9-20], the relationship between income and physical and psychological well-being has not been sufficiently explored in the long-term CRC survivor population. This relationship has increasing importance as survivorship increases and the long-term effects of permanent changes in bowel function emerge. The purpose of this analysis was to explore the unique contribution of household income to the variance explained in psychological well-being among long-term ( $\geq 5$ years) CRC survivors.

\section{METHODS}

\section{Subjects}

This study is a secondary analysis of data collected in the Health-Related Quality of Life in Long-Term Colorectal Cancer Survivors Study, which was designed to assess the subjective experience of living with an ostomy. A detailed description of the overall study methodology is presented elsewhere [21]. A cross-sectional, survey research design was employed in which 
679 respondents (284 CRC survivors with ostomies [cases]; 395 CRC survivors without ostomies [controls]) completed a mailed questionnaire that included health-related quality of life (HRQOL) scales along with socio-demographic, health, and health care utilization items. Subjects were recruited from three regions of a national prepaid group practice health maintenance organization and a 52\% (679/1308) response rate was obtained. For the purpose of this secondary analysis, the case and control subjects were combined and complete data were available for all required variables from 588 subjects. The study was approved by the human subjects committees at each site.

\section{Measures}

Medical records and subject self-report were the data sources. A comprehensive sociodemographic and medical history was obtained for study participants from each site's automated information system. Data regarding the subjects' age, sex, and ostomy status were obtained from the information system. In addition, the Charlson-Deyo comorbidity index [22] was constructed from ICD-9-CM codes from outpatient and inpatient encounters during the year prior to completion of the study questionnaire. A Charlson-Deyo index score of 0 indicates no comorbidities are present; higher index scores indicate a higher comorbidity burden.

The self-reported measures included the modified City of Hope Quality of Life (mCOH-QOL)Ostomy questionnaire [23] and the SF-36v2 [24], both of which have demonstrated high reliability and validity in numerous patient samples [23-28]. Along with socio-demographic information (e.g., education, race/ethnicity, partner status, and household income), the $\mathrm{mCOH}$ QOL-Ostomy questionnaire provides scale scores for the following four domains: physical, psychological, social, and spiritual well-being. The scale scores are on an 11-point scale where $0=$ poorest and $10=$ best [23]. The score of the $\mathrm{mCOH-QOL-Ostomy} \mathrm{questionnaire's}$ psychological well-being (PWB) scale, which has 13 items covering a variety of emotional and cognitive issues (e.g., depression, anxiety, hope, fear of recurrence, remembering), was the dependent variable in this analysis. Due to the inclusion of ostomy-specific items, an abridged version of the mCOH-QOL-Ostomy questionnaire was used for the control subjects. The PWB scale in the abridged version has one less item than the unabridged version; however, there is evidence that the removal of the ostomy-specific item did not meaningfully diminish the reliability or construct validity of the scale [21]. The response categories for self-reported annual household income on the mCOH-QOL-Ostomy questionnaire were "Less than $\$ 15,000, ” \$ 15,000$ to $\$ 30,000$, , “\$30,001 to $\$ 50,000$," “\$50,001 to $\$ 75,000$," “75,001 to $\$ 100,000$," and "Greater than $\$ 100,000 . "$

The SF-36v2 produces scores for eight multi-item scales and physical (PCS) and mental (MCS) component summary scores based on a population norm-based scoring function [24]. Only the PCS score was used in this analysis as an independent variable in the model. It was calculated with QualityMetric's Health Outcomes Scoring Software 2.0 (copyright QualityMetric, Lincoln, Rhode Island, USA 2004-2007).

\section{Statistical Analysis}

To assess the unique contribution that household income makes to PWB, a hierarchical linear regression model was constructed. In the model, we explored the contribution of income to the variance in the $\mathrm{mCOH}-\mathrm{QOL}-$ Ostomy questionnaire's PWB score over and above the following independent variables: physical health (SF-36v2 PCS), comorbidity (Charlson-Deyo index), age, sex, race/ethnicity, education, partnered status, and presence of an ostomy.

Model 1: PWB score $=\beta_{0}+\beta_{\mathrm{PCS}}+\beta_{\text {Charlson-Deyo }}+\beta_{\text {Age }}+\beta_{\text {Sex }}+\beta_{\text {Race/ethnicity }}+\beta_{\text {Education }}+$ $\beta_{\text {Partnered Status }}+\beta_{\text {Ostomy }}$ 
Model 2: PWB score $=\beta_{0}+\beta_{\text {PCS }}+\beta_{\text {Charlson-Deyo }}+\beta_{\text {Age }}+\beta_{\text {Sex }}+\beta_{\text {Race/ethnicity }}+\beta_{\text {Education }}+$ $\beta_{\text {Partnered Status }}+\beta_{\text {Ostomy }}+\beta_{\text {Income }}$

\section{RESULTS}

After accounting for the proportion of variance in PWB explained by the other independent variables in the model (Table), the additional variance explained by income was significant $\left(\mathrm{R}^{2}\right.$ increased from 0.228 to $\left.0.250 ; \mathrm{p}=0.006\right)$. When compared to those in the highest household income category $(>\$ 100,000)$, subjects in the lowest income category $(<\$ 15,000)$ had a 0.82 point lower PWB score on the 11-point scale. Significant positive predictors of PWB were SF-36v2 PCS score, age, and absence of an ostomy.

\section{DISCUSSION}

Our exploratory analysis demonstrated a significant relationship between household income and PWB in CRC survivors. However, the study has several limitations, including the use of household income rather than income directly attributable to the CRC survivor. The use of household income is based on the unitary theory of the household. Under this model, choices made by the household (e.g., obtaining healthcare for a household member) are made irrespective of the source of income [29]. It is also interesting to note that the variables 'married/ partnered' and 'some graduate school' were not statistically significant predictors in the model to which income was added hierarchically. This change may reflect the positive correlation between household income and these two variables. In addition, we captured the associations between PWB and household income, and all other omitted factors correlated with income (e.g., IQ, willingness to work hard).

A dominant belief among medical scientists is that the evidence points to a causal relation between sustained economic hardship and poor health and well-being [16-19]. Conversely, economists have argued that the causality may run primarily from health to SES, through factors such as the ability to work and to consume more efficiently and thereby accumulate wealth $[20,21]$. Hence, we realize that our dependent variable (i.e., psychological well-being) might influence our predictor variable (i.e., household income). However, we did not intend our exploratory analysis to lead to causal inferences.

Based on the work of Norman et al. [30], the 0.82 difference in PWB score between the highest and lowest household income categories is not only statistically significant, but clinically meaningful as well. This finding merits further consideration when attempting to interpret patient-reported outcomes, particularly HRQOL. The findings suggest that for non-randomized group comparisons of HRQOL, income should, at the very least, be included as a control variable in the analysis. There may be effects of SES on health and well-being and vice versa. Although this dynamic association may exist, it is not necessary to make a priori assumptions about which association is stronger [31]. Researchers must be aware of this relationship and control for resulting endogeneity.

\section{Acknowledgements}

The data used for this research were collected as part of a study conducted by the Southern Arizona Veterans Affairs Health Care System (SAVAHCS)/Kaiser Permanente Collaborative Research Group, which was made possible by Grant Number R01 CA106912 from the National Cancer Institute in collaboration with resources and the use of facilities provided at the Southern Arizona Veterans Affairs Health Care System, Tucson, Arizona. Additional support was provided through the Arizona Cancer Center Support Grant CA023074 and by the College of Pharmacy at the University of Arizona. The views expressed in this paper are those of the authors and do not necessarily represent the views of Kaiser Permanente, the Department of Veterans Affairs, or the University of Arizona. 


\section{Abbreviations}

CRC, colorectal cancer; SES, socioeconomic status; mCOH-QOL-Ostomy, modified City of Hope Quality of Life-Ostomy questionnaire; HRQOL, Health-related quality of life; PCS, SF-36 physical component summary scale; MCS, SF-36 mental component summary scale; PWB, psychological well-being.

\section{REFERENCES}

1. May JH, Cunningham PJ. Tough trade-offs: medical bills, family finances and access to care. Issue Brief Cent Stud Health Syst Change 2004:1-4.

2. Himmelstein DU, Warren E, Thorne D, et al. Illness and injury as contributors to bankruptcy. Health Aff (Millwood) 2005;(Suppl Web Exclusives):W5-63-W65-73. [PubMed: 15689369]

3. Dranove D, Millenson ML. Medical bankruptcy: myth versus fact. Health Aff (Millwood) 2006;25:w74-83. [PubMed: 16507555]

4. Ell K, Xie B, Wells A, et al. Economic stress among low-income women with cancer. Cancer 2008;112:616-25. [PubMed: 18085642]

5. Short PF, Mallonee EL. Income disparities in the quality of life of cancer survivors. Med Care 2006;44:16-23. [PubMed: 16365608]

6. Mariotto AB, Yabroff KR, Feuer EJ, et al. Projecting the number of patients with colorectal carcinoma by phases of care in the US: 2000-2020. Cancer Causes Control 2006;17:1215-26. [PubMed: 17111252]

7. Solomon MJ, Pager CK, Keshava A, et al. What do patients want? Patient preferences and surrogate decision making in the treatment of colorectal cancer. Dis Colon Rectum 2003;46:1351-7. [PubMed: 14530674]

8. Pachler J, Wille-Jørgensen P. Quality of life after rectal resection for cancer, with or without permanent colostomy. The Cochrane Database of Systematic Reviews 2005, Issue 2. Art. No.: Sys Rev 2004; (3):CD004323.pub3.DOI: 10.1002/14651858.CD004323.pub3

9. Adler NE, Boyce T, Chesney MA, Folkman S, Syme L. Socio-economic inequalities and health. Journal of the American Medical Association 1993;269:3140-3145. [PubMed: 8505817]

10. Backlund E, Sorlie PD, Johnson NJ. The shape of the relationship between income and mortality in the United States: Evidence from the National Longitudinal Mortality Study. Annals of Epidemiology 1996;6:1-9. [PubMed: 8680618]

11. Elo IT, Preston SH. Educational differentials in mortality: United States, 1979-85. Social Science and Medicine 1995;42:47-57. [PubMed: 8745107]

12. Hemingway H, Nicholson A, Marmot M. The impact of socioeconomic status on health functioning as assessed by the SF-36 Questionnaire: The Whitehall II Study. American Journal of Public Health 1997;87:1484-1490. [PubMed: 9314801]

13. Lagasse R, Humbelt CP, Lenaerts A, Godin I, Moens GFG. Health and social inequalities in Belgium. Social Science and Medicine 1990;31:237-248. [PubMed: 2218604]

14. Wolfson M, Rowe G, Gentleman JE, Tomiak M. Career earnings and death: A longitudinal analysis of older Canadian men. Journal of Gerontology 1993;48:S167-179. [PubMed: 8315241]

15. Carr-Hill R. The inequalities in health debate: A critical review of the issues. Journal of Social Policy 1987;16:509-542. [PubMed: 10302098]

16. Wilkinson, RG. Socio-economic differences in mortality: Interpreting the data on their size and trends.. In: Wilkinson, RD., editor. Class and Health: Research and Longitudinal Data. Tavistock; London: 1986.

17. Williams DR. Socioeconomic differentials in health: A review and redirection. Social Psychology Quarterly 1990;53:81-99.

18. Geronimus AT, Bound J, Waidmann TA, Hillenmeier MM, Burns PB. Excess mortality among blacks and whites in the United States. New England Journal of Medicine 1996;335:1552-1558. [PubMed: 8900087]

19. Bartley M, Owen C. Relation between socioeconomic status, employment, and health during economic change, 1973-93. British Medical Journal 1996;313:445-449. [PubMed: 8776309] 
20. Smith JP. Healthy bodies and thick wallets: the dual relation between health and economic status. Journal of Economic Perspectives 1999;13(2):145-166.

21. Mohler MJ, Coons SJ, Hornbrook MC, Herrinton LJ, Wendel CS, Grant M, Krouse RS. The HealthRelated Quality of Life in Long-Term Colorectal Cancer Survivors Study: objectives, methods and patient sample. Current Medical Research and Opinion 2008;24:2059-2070. [PubMed: 18544186]

22. Deyo RA, Cherkin DC, Ciol MA. Adapting a clinical comorbidity index for use with ICD-9-CM administrative databases. J Clin Epidemiol 1992;45:613-9. [PubMed: 1607900]

23. Grant M, Ferrell B, Dean G, et al. Revision and psychometric testing of the City of Hope Quality of Life-Ostomy Questionnaire. Qual Life Res 2004;13:1445-57. [PubMed: 15503840]

24. Ware, JE.; Kosinski, M.; Dewey, JE. How to Score Version Two of the SF-36 Health Survey. QualityMetric Incorporated; Lincoln, RI: 2000.

25. Krouse R, Grant M, Ferrell B, et al. Quality of life outcomes in 599 cancer and non-cancer patients with colostomies. J Surg Res 2007;138:79-87. [PubMed: 17196990]

26. Krouse RS, Mohler MJ, Wendel CS, et al. The VA Ostomy Health-Related Quality of Life Study: objectives, methods, and patient sample. Curr Med Res Opin 2006;22:781-91. [PubMed: 16684439]

27. Ware JE, Sherbourne CD. The MOS 36-item short-form health survey (SF-36). I. conceptual framework and item selection. Med Care 1992;30:473-83. [PubMed: 1593914]

28. Ware, JE. SF-36 Health Survey update.. In: Maruish, ME., editor. The use of psychological testing for treatment planning and outcomes assessment. Vol. 3rd Edition. Vol. 3. Lawrence Erlbaum Associates; Mahwah (NJ): 2004. p. 693-718.

29. Becker G. A theory of social interactions. J Polit Econ 1974;82(6):1063-1093.

30. Norman GR, Sloan JA, Wyrich KW. Interpretation of changes in health-related quality of life: the remarkable universality of half a standard deviation. Medical Care 2003;41:582-592. [PubMed: 12719681]

31. Lynch JW, Kaplan GA, Shema SJ. Cumulative impact of sustained economic hardship on physical, cognitive, psychological, and social functioning. New England Journal of Medicine 1997;337:18891895. [PubMed: 9407157] 
Table

Hierarchical Regression Results; Dependent Variable is Psychological Well-being (PWB).

\begin{tabular}{|c|c|c|c|c|}
\hline & \multicolumn{2}{|c|}{ Model 1 (n=588) } & \multicolumn{2}{|c|}{ Model 2 (n=588) } \\
\hline & Coefficient (SE) & $95 \% \mathrm{CI}$ & Coefficient (SE) & $95 \% \mathrm{CI}$ \\
\hline SF-36v2 PCS Score & $0.06(0.01)^{* *}$ & 0.05 to 0.07 & $0.06(0.01)^{* *}$ & 0.04 to 0.07 \\
\hline Charlson-Deyo $1^{a}$ & $0.26(0.19)$ & -0.15 to 0.61 & $0.25(0.19)$ & -0.13 to 0.63 \\
\hline Charlson-Deyo $2^{a}$ & $-0.08(0.16)$ & -0.42 to 0.22 & $-0.16(0.16)$ & -0.47 to 0.16 \\
\hline Charlson-Deyo $3^{a}$ & $-0.28(0.24)$ & -0.90 to 0.05 & $-0.43(0.24)$ & -0.90 to 0.04 \\
\hline Charlson-Deyo $4^{a}$ & $0.14(0.31)$ & -0.50 to 0.73 & $0.03(0.31)$ & -0.59 to 0.63 \\
\hline Charlson-Deyo $5^{a}$ & $-0.45(0.40)$ & -1.22 to 0.35 & $-0.36(0.40)$ & -1.14 to 0.42 \\
\hline Charlson-Deyo $6^{a}$ & $-0.61(0.34)$ & -1.18 to 0.17 & $-0.49(0.34)$ & -1.15 to 0.18 \\
\hline Charlson-Deyo $7^{a}$ & $-0.43(0.57)$ & -1.83 to 0.43 & $-0.77(0.57)$ & -1.89 to 0.35 \\
\hline Charlson-Deyo $8^{a}$ & $-0.32(0.76)$ & -1.83 to 1.13 & $-0.41(0.75)$ & -1.88 to 1.06 \\
\hline Charlson-Deyo $9^{a}$ & $1.62(1.07)$ & -0.50 to 3.68 & $1.73(1.06)$ & -0.35 to 3.81 \\
\hline Age & $0.03(0.01)^{*}$ & 0.01 to 0.04 & $0.03(0.01)^{* *}$ & 0.02 to 0.04 \\
\hline Female & $0.02(0.13)$ & -0.17 to 0.35 & $0.08(0.13)$ & -0.18 to 0.35 \\
\hline Hispanic $^{b}$ & $0.18(0.30)$ & -0.41 to 0.76 & $0.11(0.30)$ & -0.47 to 0.70 \\
\hline African American $^{b}$ & $-0.31(0.37)$ & -1.13 to 0.33 & $-0.33(0.37)$ & -1.06 to 0.40 \\
\hline $\operatorname{Asian}^{b}$ & $-0.30(0.22)$ & -0.70 to 0.15 & $-0.22(0.22)$ & -0.65 to 0.20 \\
\hline Other $^{b}$ & $-0.28(0.29)$ & -0.77 to 0.36 & $-0.18(0.29)$ & -0.74 to 0.39 \\
\hline High school/GED ${ }^{c}$ & $0.31(0.23)$ & -0.13 to 0.75 & $0.33(0.23)$ & -0.12 to 0.77 \\
\hline Vocational/business ${ }^{c}$ & $0.22(0.32)$ & -0.49 to 0.76 & $0.14(0.32)$ & -0.48 to 0.75 \\
\hline Some college ${ }^{c}$ & $0.32(0.23)$ & -0.16 to 0.74 & $0.21(0.24)$ & -0.25 to 0.68 \\
\hline College graduate ${ }^{c}$ & $0.48(0.25)$ & -0.05 to 0.93 & $0.26(0.26)$ & -0.24 to 0.76 \\
\hline Some graduate school ${ }^{c}$ & $0.58(0.31)^{*}$ & 0.04 to 1.27 & $0.46(0.32)$ & -0.17 to 1.09 \\
\hline Graduate degree $^{c}$ & $0.36(0.26)$ & -0.12 to 0.90 & $0.18(0.27)$ & -0.36 to 0.71 \\
\hline Married/partnered & $0.34(0.14)^{* *}$ & 0.06 to 0.60 & $0.22(0.15)$ & -0.07 to 0.51 \\
\hline Ostomy & $-0.32(0.13)^{*}$ & -0.53 to -0.04 & $-0.29(0.13)^{*}$ & -0.54 to -0.05 \\
\hline$\$ 15,000-\$ 30,999^{d}$ & & & $0.04(0.24)$ & -0.43 to 0.51 \\
\hline$\$ 31,000-\$ 50,999^{d}$ & & & $0.08(0.25)$ & -0.42 to 0.58 \\
\hline$\$ 51,000-\$ 75,999^{d}$ & & & $0.50(0.28)$ & -0.05 to 1.06 \\
\hline$\$ 76,000-\$ 100,000^{d}$ & & & $0.81(0.32)^{*}$ & 0.17 to 1.44 \\
\hline$>\$ 100,000^{d}$ & & & $0.82(0.35)^{*}$ & 0.13 to 1.51 \\
\hline Constant & $2.76(0.70)^{*}$ & & $2.31(0.73)^{* *}$ & 0.89 to 3.73 \\
\hline $\mathbf{F}$ & $6.92(\mathrm{p}<0.001)$ & & $6.41(\mathrm{p}<0.001)$ & \\
\hline R-squared & 0.2278 & & 0.2500 & \\
\hline Change in R-squared & & & $0.0222(\mathrm{p}=0.006)$ & \\
\hline
\end{tabular}

Reference groups:

$a_{\text {Charlson-Deyo }=0}$ 
$b_{\text {non-Hispanic White }}$

${ }^{c}<$ High School

$d_{<\$ 15 \mathrm{k}}$

$\mathrm{p}<0.05$

* $\mathrm{p}<0.01$ 